\title{
Gastrointestinal stromal tumors regularly express synaptic vesicle proteins: evidence of a neuroendocrine phenotype
}

\author{
Per Bümming, Ola Nilsson ${ }^{1}$, Håkan Ahlman, Anna Welbencer ${ }^{1}$, Mattias \\ $K$ Andersson ${ }^{1}$, Katarina Sjölund and Bengt Nilsson
}

Lundberg Laboratory for Cancer Research, Departments of Surgery and ${ }^{1}$ Pathology, Sahlgrenska Academy at the University of Göteborg, Sahlgrenska University Hospital, SE-413 45 Göteborg, Sweden

(Correspondence should be addressed to O Nilsson; Email: ola.nilsson@llcr.med.gu.se)

\begin{abstract}
Gastrointestinal stromal tumors (GISTs) are thought to originate from the interstitial cells of Cajal, which share many properties with neurons of the gastrointestinal tract. Recently, we demonstrated expression of the hormone ghrelin in GIST. The aim of the present study was therefore to evaluate a possible neuroendocrine phenotype of GIST. Specimens from 41 GISTs were examined for the expression of 12 different synaptic vesicle proteins. Expression of synaptic-like microvesicle proteins, e.g., Synaptic vesicle protein 2 (SV2), synaptobrevin, synapsin 1, and amphiphysin was demonstrated in a majority of GISTs by immunohistochemistry, western blotting, and quantitative reversetranscriptase PCR. One-third of the tumors also expressed the large dense core vesicle protein vesicular monoamine transporter 1 . Presence of microvesicles and dense core vesicles in GIST was confirmed by electron microscopy. The expression of synaptic-like microvesicle proteins in GIST was not related to risk profile or to KIT/platelet derived growth factor alpha (PDGFRA) mutational status. Thus, GISTs regularly express a subset of synaptic-like microvesicle proteins necessary for the regulated secretion of neurotransmitters and hormones. Expression of synaptic-like micro-vesicle proteins, ghrelin and peptide hormone receptors in GIST indicate a neuroendocrine phenotype and suggest novel possibilities to treat therapy-resistant GIST.
\end{abstract}

Endocrine-Related Cancer (2007) 14 853-863

\section{Introduction}

Gastrointestinal stromal tumors (GIST) are thought to originate from stem cells that differentiate toward the interstitial cells of Cajal (ICC; Kindblom et al. 1998, Sircar et al. 1999, Lee et al. 2001). The ICC form a complex cellular network that is positioned between nerve endings and smooth muscle cells in the intestinal wall, and functions as a pacemaker system controlling motility and possibly also neurotransmission (Vannucchi 1999). The tyrosine kinase receptor KIT is of vital importance for normal development of the intestinal pacemaker system (Huizinga et al. 1995, Hirota et al. 1998). Both ICC and GISTs express KIT, and mutations in the KIT gene are regarded as an early pathogenetic event in the tumorigenesis of GIST. Ultrastructural studies have demonstrated similarities between ICC and GISTs with presence of numerous cytoplasmic vesicles
(Kindblom et al. 1998, Komuro 1999). GIST have dense core granules, or small empty vesicles, which resemble synaptic vesicles (Erlandson et al. 1996).

Neuroendocrine function is defined by the presence of a regulated secretory pathway by which neurotransmitters and hormones are released upon stimulation. Two types of regulated secretory pathways have been characterized. One pathway utilizes large dense core vesicles (LDCVs) containing e.g. chromogranins, vesicular monamine transporters (VMAT 1 and 2), and synaptic vesicle protein 2 (SV2), and the other pathway uses synaptic-like microvesicles (SLMVs) containing e.g. synapsin 1, synaptophysin, synaptobrevin, and SV2 (Rindi et al. 2004). Neurons predominantly contain SLMV, while neuroendocrine cells frequently contain both LDCV and SLMV.

Chromogranin A (CgA), the major acidic protein of chromaffin granules, is present in most neuroendocrine 
cell types, both normal and neoplastic (Lloyd \& Wilson 1983). The expression of synaptophysin, initially found in small vesicle membranes of neurons, has also been demonstrated in normal and neoplastic neuroendocrine cells (Jahn et al. 1985). Expression of $\mathrm{CgA}$ and/or synaptophysin in tumors has therefore been used as histopathologic criterion for neuroendocrine differentiation.

Here, we report the expression profile of synaptic vesicle proteins, demonstrating regular presence of SLMV, but not of LDCV, in GIST.

\section{Materials and methods}

\section{Criteria for GIST - diagnosis and classification}

Criteria for the diagnosis of GIST were: (1) primary tumor site in the gastrointestinal tract and (2) characteristic histopathology including immunoreactivity toward KIT (CD 117). Based on tumor size and mitotic rate, the tumors were classified as very low-risk, low-risk, intermediate-risk, or high-risk GIST (Fletcher et al. 2002). To these four risk groups, we added a fifth, overtly malignant, which included all tumors with proven metastases at the time of diagnosis (Nilsson et al. 2005). In the present study, we separated the tumors into low-risk profile (very low-, low-, and intermediate-risk GIST, $n=29$ ) and high-risk profile (high-risk and overtly malignant GIST, $n=12$ ).

Mutation analysis was performed on all 41 tumors as previously described (Andersson 2005). The study was approved by the Ethical Trial Committee of Göteborg University and performed in accordance with the Helsinki Declaration of 1975.

\section{Immunohistochemistry}

Forty-one tumors (low-risk profile, $n=29$; high-risk profile, $n=12$ ) were analyzed by immunohistochemistry (IHC). Staining was performed on paraffinembedded specimens. In patients with low-risk profile GIST, 27 primaries, one local recurrence and one metastasis were used for analysis. In patients with high-risk profile GIST, seven primaries, one local recurrence, and four metastases were used for analysis. Sections $(4 \mu \mathrm{m})$ were subjected to heat-induced antigen retrieval using microwave treatment (TrisEDTA, pH 9). Details of primary antibodies are given in Table 1. Bound antibodies were visualized using EnVision + System-HRP labeled polymer (DakoCytomation, Dako, Glostrup, Denmark). Immunolabeling was graded as follows: $0,<1 \%$ positive tumor cells; $1+, 1-24 \%$ positive tumor cells; $2+, 25-75 \%$ positive tumor cells; $3+,>75 \%$ positive tumor cells. Normal tissue (brain and gut) and endocrine tumors (ileal carcinoid and adrenal pheochromocytoma) served as positive controls for IHC.

\section{Confocal laser scanning microscopy}

Formalin-fixed paraffin embedded specimens from normal stomach $(n=2)$, normal ileum $(n=2)$, normal colon $(n=2)$, and GIST (gastric; low-risk profile, $n=1$ and high-risk profile, $n=2$ ) were analyzed by confocal laser scanning microscopy. Sections $(4 \mu \mathrm{m})$ were subjected to heat-induced antigen retrieval using microwave treatment (Tris-EDTA, $\mathrm{pH}$ 9) followed by incubation with a mixture of primary antibodies (antiCD117 1:20 and anti-SV2 1:100), rinsing in PBS and incubated with a mixture of secondary antibodies conjugated with Alexa Fluor 594 (goat anti-rabbit, 1:2000; A11037, Invitrogen) and Alexa Fluor 488 (goat anti-mouse, 1:2000; A11029, Invitrogen, Carlsbad, CA, USA). Coverslips were mounted with ProLong Gold antifade reagent with DAPI (P36931, Molecular Probes, Eugene, OR, USA). The fluorescent cells were analyzed by confocal microscopy using a Zeiss LSM 510 META system with the LSM-FCS software supplied by the manufacturer (Carl Zeiss, Jena, Germany). Emission spectra were recorded with the META multichannel detector using the following settings: Hoechst 33258, Diode laser $405 \mathrm{~nm}$ excitation, $422-476 \mathrm{~nm}$ emission detection; Alexa Fluor 488, Argon laser $488 \mathrm{~nm}$ excitation, 497-550 nm emission detection and Alexa Fluor 594, DPSS-laser $561 \mathrm{~nm}$ excitation, 583-668 nm emission detection. Images were recorded with an optical section of $0.8 \mu \mathrm{m}$ using a Plan-FLUAR 100X/1.45 N.A. oil immersion objective.

\section{Electron microscopy}

Specimens from GIST (gastric; low-risk profile, $n=1$ and high-risk profile, $n=1$ ) were fixed in $2.5 \%$ glutaraldehyde in $0.1 \mathrm{M}$ cacodylate buffer for 12 days, followed by postfixation in $1 \%$ osmium tetroxide for $1 \mathrm{~h}$. Specimens were dehydrated and embedded in epoxy resin (TAAB 812). Ultrathin sections were placed on copper grids, contrasted with uranyl acetate and lead citrate before examination and photography in a Philips CM12 electron microscope.

\section{Western blot}

Biopsies from ten patients with GIST were analyzed by western blotting (low-risk profile, $n=4$; high-risk profile, $n=6$ ). In patients with low-risk profile GIST, only primary tumors were analyzed. In patients with high-risk profile GIST, one primary, one local 
Table 1 Antibodies used for immunohistochemistry and western blot

\begin{tabular}{|c|c|c|c|c|c|c|}
\hline Antibody & Species & Dilution (IHC) & Dilution (WB) & Clone & Code no. & Source \\
\hline Anti-amphiphysin & Mouse & $1: 250$ & $1: 250$ & 3 & VAM-SV030 & $\begin{array}{l}\text { Nordic Biosite AB, } \\
\text { Täby, Sweden }\end{array}$ \\
\hline Anti- $\beta$-actin & Mouse & - & $1: 1000$ & mAbcam8226 & AB8226 & $\begin{array}{l}\text { Abcam Ltd, Cambridge, } \\
\text { UK }\end{array}$ \\
\hline Anti-CD117 & Rabbit & $1: 100$ & $1: 500$ & - & A4502 & $\begin{array}{l}\text { DakoCytomation } \\
\text { Denmark A/S, } \\
\text { Glostrup, Denmark }\end{array}$ \\
\hline Anti-CgA & Mouse & $1: 1600$ & - & LK2H10 & MAB319 & $\begin{array}{l}\text { Chemicon International } \\
\text { Inc., Temecula, CA, } \\
\text { USA }\end{array}$ \\
\hline Anti-GAP43 & Mouse & $1: 20$ & - & $1 \mathrm{G} 7$ & NCL-GAP43 & $\begin{array}{l}\text { Novocastra Labora- } \\
\text { tories Ltd, Newcastle } \\
\text { upon Tyne, UK }\end{array}$ \\
\hline Anti-SNAP25 & Mouse & $1: 2000$ & - & SP12 & NB09 & $\begin{array}{l}\text { Oncogene Research } \\
\text { Products, Darmstadt, } \\
\text { Germany }\end{array}$ \\
\hline Anti-SV2 $^{a}$ & Mouse & $1: 1000$ & $1: 10000$ & $\mathrm{SP} 2 / 0$ & SV2 & $\begin{array}{c}\text { Developmental Studies } \\
\text { Hybridoma Bank, } \\
\text { lowa city, IA, USA }\end{array}$ \\
\hline Anti-synapsin 1 & Mouse & $1: 100$ & $1: 100$ & A10C & NB08 & $\begin{array}{l}\text { Oncogene Research } \\
\text { Products }\end{array}$ \\
\hline Anti-synapsin 2A & Mouse & $1: 500$ & - & 1 & S56820 & $\begin{array}{l}\text { Transduction Labora- } \\
\text { tories, Lexington, KY, } \\
\text { USA }\end{array}$ \\
\hline Anti-synaptobrevin ${ }^{\mathrm{b}}$ & Mouse & $1: 1000$ & $1: 1000$ & SP10 & MMS-616R & Nordic Biosite AB \\
\hline Anti-synaptophysin & Mouse & $1: 160$ & - & SY38 & M0776 & $\begin{array}{l}\text { DakoCytomation } \\
\text { Denmark A/S }\end{array}$ \\
\hline Anti-syntaxin & Mouse & $1: 400$ & - & SP8 & MAB336 & $\begin{array}{l}\text { Chemicon International } \\
\text { Inc. }\end{array}$ \\
\hline Anti-VMAT1 & Goat & $1: 1000$ & 1:2000 & - & Sc-7718 & $\begin{array}{l}\text { Santa Cruz Bio- } \\
\text { technology Inc., } \\
\text { Santa Cruz, CA, USA }\end{array}$ \\
\hline Anti-VMAT2 & Rabbit & $1: 1000$ & 1:2000 & - & $\mathrm{AB} 1767$ & $\begin{array}{l}\text { Chemicon International } \\
\text { Inc. }\end{array}$ \\
\hline
\end{tabular}

IHC, immunohistochemistry; WB, western blot; CD 117, KIT receptor; CgA, chromogranin A; GAP43, growth-associated phosphoprotein 43; SNAP25, synaptosome-associated protein of $25 \mathrm{kDa}$; SV2, synaptic vesicle protein 2; VMAT1 and 2, vesicular monoamine transporter 1 and 2.

aThe antibody cross-reacts with SV2A, SV2B, and SV2C.

${ }^{\mathrm{b}}$ The antibody cross-reacts with synaptobrevin 1 and 2.

recurrence and four metastases were used for analysis. Neuroendocrine tumors served as positive controls (sporadic adrenal pheochromocytoma, well-differentiated endocrine carcinoma of the ileum-midgut carcinoid, and sporadic endocrine pancreatic carcinoma-malignant insulinoma). Western blot was performed as previously described (Jakobsen et al. 2002). Briefly, tumor tissues (200 mg/sample) were homogenized and assayed for protein content according to Bradford. Aliquots of proteins $(40 \mu \mathrm{g})$ were separated by electrophoresis on precast polyacrylamide gels (10\% NuPAGE Bis-Tris gels; Invitrogen) and transferred to polyvinyl difluoride membranes using a NOVEX blotting system (Invitrogen). The membranes were incubated with primary antibodies (Table 1) at
$+4{ }^{\circ} \mathrm{C}$ overnight, followed by incubation with alkaline phosphatase-conjugated secondary antibodies and then with CDP-Star (Tropix, Bedford, MA, USA) as substrate. The membranes were exposed to hyperfilm ECL (Amersham Pharmacia Biotech, Buckinghamshire, UK) at room temperature for $10-300 \mathrm{~s}$. Molecular weight markers (See-Blue Plus 2 and MagicMark; Invitrogen) were used to calculate the apparent size of immunoreactive proteins.

\section{Quantitative reverse transcriptase PCR (Q-PCR)}

\section{RNA extraction}

Biopsies from ten patients with GIST were analyzed by Q-PCR (low-risk profile, $n=5$; high-risk profile, 
$n=5$ ). In patients with low-risk profile GIST, four primaries, and one local recurrence were used for analysis. In patients with high-risk profile GIST, one primary, one local recurrence, and three metastases were used for analysis. A human midgut carcinoid cell line (GOT1; Kölby et al. 2001) and a human colorectal adenocarcinoma cell line (Colo 205-CCL-222; ATCC, Manassas, VA, USA) were used as calibrators for Q-PCR assay. Colorectal adenocarcinoma (primaries, $n=2$; lymph node metastasis, $n=1$ ) and welldifferentiated endocrine carcinoma of the ileum (midgut carcinoid; primary, $n=1$; liver metastases, $n=2$ ) served as control tumors in the Q-PCR analysis. Total RNA was prepared by homogenizing tumor biopsies in Trizol Reagent (Invitrogen; cat. no. 15596026) using a Tissuelyser (QIAGEN, Solna, Sweden; cat. no. 85220) followed by RNA purification using FastRNA Kit, Green (QBIOgene, Irvine, CA, USA; cat. no. 6040-600). Total RNA from cultured cell lines was prepared using Trizol and the RNeasy Mini Kit (QIAGEN, cat. no. 74104). The quality of extracted RNA was examined by gel electrophoresis (Agilent 2100 Bioanalyser, Agilent Technologies, Santa Clara, CA, USA; cat. no. 62938-90030). Before cDNA synthesis, RNA samples were subjected to DNase treatment using DNA-Free (Ambion Inc., Austin, TX, USA; cat. no. 1906).

\section{cDNA synthesis}

cDNA was synthesized from extracted RNA using TaqMan reverse transcription reagents according to the manufacturer's protocol (Applied Biosystems, Foster City, CA, USA; cat. no. N808-0234). For every cDNA synthesis reaction, a control reaction containing the same components was run, but without reverse transcriptase. The tubes were placed in a GeneAmp PCR System 2400 (Applied Biosystems) and a onecycle PCR was performed using the following parameters: $25^{\circ} \mathrm{C}$ for $10 \mathrm{~min}, 48^{\circ} \mathrm{C}$ for $30 \mathrm{~min}$, $95^{\circ} \mathrm{C}$ for $5 \mathrm{~min}$, followed by incubation at $4{ }^{\circ} \mathrm{C}$. The cDNA was kept at $-20{ }^{\circ} \mathrm{C}$ until assay.

\section{Primers and probes}

Primers and probes were purchased from Applied Biosystems. Hs00249911_m1 (vesicle-associated membrane protein 1: VAMP1; synaptobrevin 1), Hs00360269_m1 (vesicle-associated membrane protein 2: VAMP2; synaptobrevin 2), Hs00155723_m1 (amphiphysin: AMPH), Hs00199577_m1 (synapsin 1: SYN1), Hs00372069_m1 (synaptic vesicle glycoprotein 2A: SV2A), Hs00174029_m1 (v-kit: KIT), Hs00154441_ml (CgA: CHGA), Hs00300531_m1 (synaptophysin: SYP), Hs00161839_ml (vesicular monoamine, member 1: SLC18A1 solute carrier family 18: VMAT1), Hs00161858_ml (vesicular monoamine, member 2: SLC18A2 solute carrier family 18: VMAT2). $\beta$-Actin primers and probe were used as a control (TaqMan $\beta$-actin Control Reagent, cat. no. 401846).

\section{Real-time PCR assay}

The PCR assays were performed in 96-well optical plates with closed optical caps, using an ABI Prism 7700. A master mix was prepared for the PCR reactions, using $2 \times$ Assay Mix containing primers, probes and TaqMan Universal PCR Master Mix (part. no 4304437).

Table 2 Clinicopathological data on 41 patients with gastrointestinal stromal tumors (GIST)

\begin{tabular}{lll}
\hline & Low-risk profile GIST $(\mathrm{VL}, \mathrm{L}, \mathrm{Im}),(n=29)$ & High-risk profile GIST $(\mathrm{H}, \mathrm{OM}),(n=12)$ \\
\hline Male/female & $17 / 12$ & $8 / 4$ \\
Age (years) & 65 & 58 \\
Tumor site (\%) & S: 62, SI: 24 & S: 33 , SI: $67^{*}$ \\
Tumor size (cm) & 4.5 & $18^{\ddagger}$ \\
Mitotic rate/50 HPF & $2-5$ & $6-10^{\dagger}$ \\
Ki67max(\%) & 1 & $125^{\ddagger}$ \\
Morphology $(n)$ & Spindled: 17 & Spindled: 4 \\
& Epithelioid: 4 & Epithelioid: 2 \\
& Mixed: 8 & Mixed: 6 \\
KIT/PDGFRA mutation $(\mathrm{n})$ & Overall: 19 & Overall: 8 \\
& KIT ex 11 deletion: 8 & KIT ex 11 deletion: 6 \\
& KIT ex 11 duplication: 5 & KIT ex 11 duplication: 1 \\
& KIT ex 11 substitution: 2 & KIT ex 11 substitution: 1 \\
& KIT ex 9 duplication: 3 & \\
\hline
\end{tabular}

$\mathrm{H}$, high-risk; HPF, high-power fields; Im, intermediate-risk; L, low-risk; OM, overtly malignant; PDGFRA, platelet derived growth factor alpha; S, stomach; SI, small intestine; VL, very-low-risk. ${ }^{*} P<0.05$ (Fisher's exact test). ${ }^{\dagger} P<0.001$ (Fisher's exact test). ${ }^{\ddagger} P<0.001$ (Mann-Whitney test). The continuous data shown are median values. 
Table 3 Immunohistochemical demonstration of KIT and synaptic vesicle proteins in 41 gastrointestinal stromal tumors (GISTs)

\begin{tabular}{llll}
\hline Marker & Protein & Low-risk profile $(\mathrm{VL}, \mathrm{L}, \mathrm{Im}),(n=29)$ & High-risk profile $(\mathrm{H}, \mathrm{OM}),(n=12)$ \\
\hline GIST & KIT $(\mathrm{CD} 117)$ & $29 / 29(0,2,5,22)$ & $12 / 12(0,0,1,11)$ \\
SLMV & SV2 & $27 / 29(2,6,9,12)$ & $12 / 12(0,6,5,1)$ \\
& Synapsin 1 & $25 / 26(1,4,10,11)$ & $8 / 8(0,3,2,3)$ \\
& Amphiphysin & $23 / 26(3,2,6,15)$ & $8 / 8(0,2,2,4)$ \\
& Synaptobrevin & $24 / 29(5,6,12,6)$ & $12 / 12(0,4,8,0)$ \\
& Synaptophysin & $0 / 28(28,0,0,0)$ & $0 / 9(9,0,0,0)$ \\
& Synapsin 2A & $0 / 26(26,0,0,0)$ & $0 / 10(10,0,0,0)$ \\
& Syntaxin & $0 / 29(29,0,0,0)$ & $0 / 12(12,0,0,0)$ \\
& SNAP25 & $0 / 29(29,0,0,0)$ & $0 / 12(12,0,0,0)$ \\
& GAP43 & $0 / 29(29,0,0,0)$ & $6 / 12(6,2,2,2)$ \\
& VMAT1 & $7 / 29(22,6,1,0)$ & $0 / 12(12,0,0,0)$ \\
LDCV & VMAT2 & $0 / 29(29,0,0,0)$ & $0 / 12(12,0,0,0)$ \\
& CgA & $1 / 29(28,1,0,0)$ &
\end{tabular}

The results are given as the number of positive tumors/total number of tumors. Staining patterns were divided into four categories and the number of tumors in each category is given in parentheses $(0,1+, 2+, 3+)$. The categories were as follows: $0,<1 \%$ positive cells; $1+, 1-24 \%$ positive cells; $2+, 25-75 \%$ positive cells; $3+,>75 \%$ positive cells.
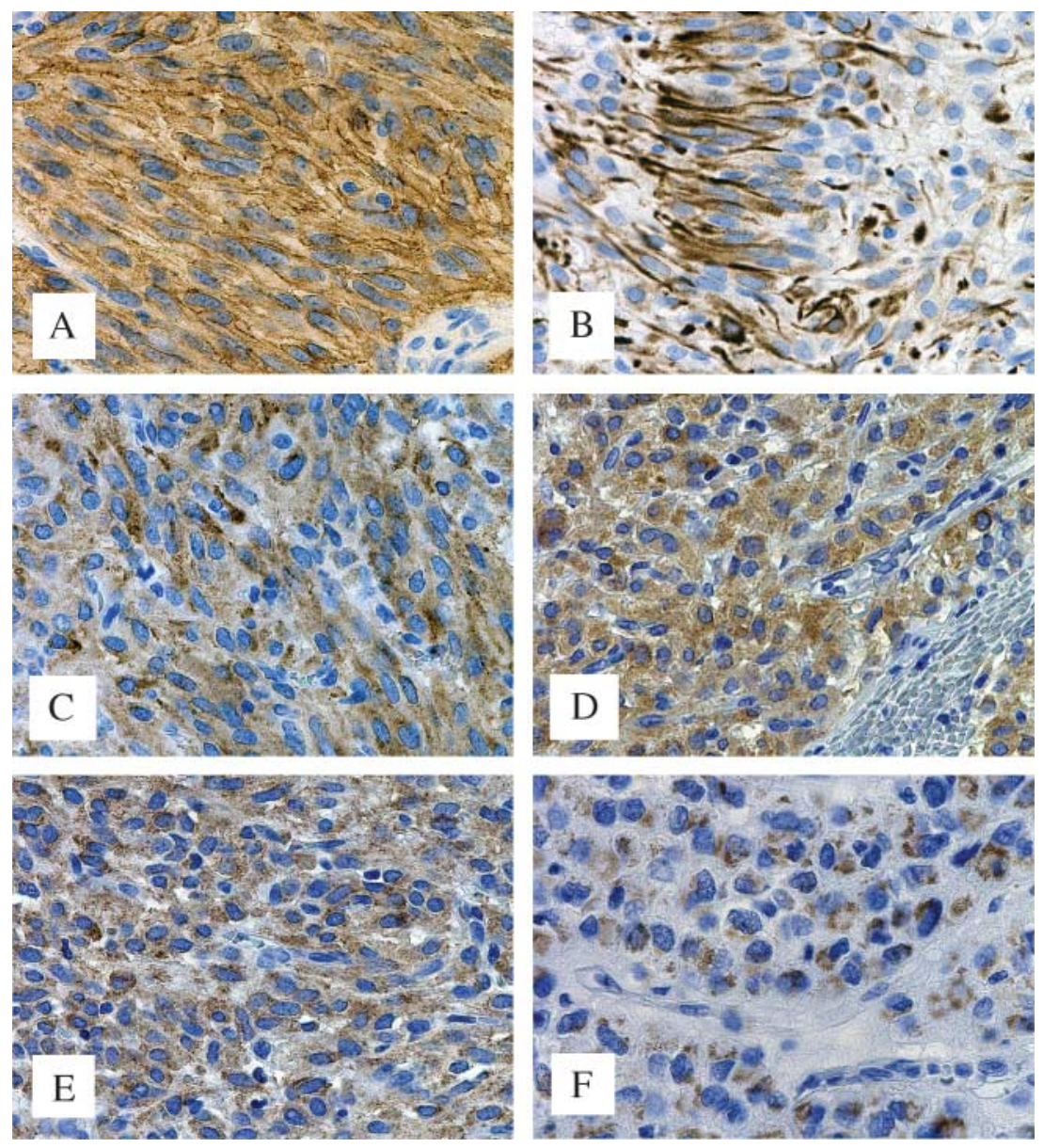

Figure 1 Immunohistochemical demonstration of CD117 (KIT) and synaptic vesicle proteins in GIST. (A) KIT: strong membrane and weak cytoplasmic staining of tumor cells. (B) synapsin 1: strong staining of tumor cell neurites and boutons. (C) SV2: moderate granular staining of tumor cell cytoplasm. (D) amphiphysin: moderate granular staining of tumor cell cytoplasm, predominantly perinuclear localization. (E) synaptobrevin: moderate granular staining of tumor cell cytoplasm. (F) VMAT1: moderate granular cytoplasmic staining of tumor cells, mainly of the perinuclear Golgi area. Immunoperoxidase staining (EnVision+). 
Each well received $5 \mu \mathrm{l}$ cDNA and $40 \mu \mathrm{l}$ master mix. The samples were subjected to an initial heating for $2 \mathrm{~min}$ at $50{ }^{\circ} \mathrm{C}$, followed by heating for $10 \mathrm{~min}$. at $90{ }^{\circ} \mathrm{C}$. The reaction consisted of 40 cycles of $95^{\circ} \mathrm{C}$ for $15 \mathrm{~s}$ and $60^{\circ} \mathrm{C}$ for $1 \mathrm{~min}$. The samples were analyzed in triplicate.

The cycle threshold $\left(C_{\mathrm{t}}\right)$ for target genes and $\beta$-actin was determined for each sample. Values were expressed as $-\Delta C_{\mathrm{t}}$ (target gene: $\beta$-actin), or number of target copies per 1000 copies of $\beta$-actin.

\section{Statistical analysis}

Continuous data from the different groups were compared using the non-parametric Mann-Whitney $U$ test. Categorical data from different groups were compared using Fisher's exact test. All $P$-values were two-tailed. $P<0.05$ was considered statistically significant.

\section{Results}

High-risk profile GIST was associated with tumor site in the small intestine $(P<0.05)$, larger tumor size $(P<0.001)$, and higher proliferation $(\operatorname{Ki} 67 \max (\%)$ and mitotic rate) $(P<0.001)$. Clinicopathological data are given in detail in Table 2.

Positive staining for KIT was observed in all GISTs (Table 3, Fig. 1). Results of western blot showed that, in GISTs, KIT migrated as a major band with an apparent weight of $108 \mathrm{kDa}$, and with a minor band of $\sim 104 \mathrm{kDa}$ (Fig. 2). Q-PCR demonstrated high expression of KIT in all GISTs (Table 5, Fig. 3). Activating KIT mutations were found in 27 $(66 \%)$ out of 41 GISTs. There were no differences in overall KIT/PDGFRA mutation frequency between low- and high-risk profile GISTs. Details of KIT/ platelet derived growth factor alpha (PDGFRA) mutational analysis are given in Table 2.

\section{SLMV proteins are regularly expressed in GIST}

SLMV proteins were shown to be expressed in GIST, as determined by IHC, western blot, and Q-PCR. Positive staining for SV2 was observed in the majority of GISTs (Table 3). In positive tumors, moderate to strong staining was observed in the cytoplasm of tumor cells, with a granular pattern (Fig. 1). Western blot showed that SV2 migrates as a broad band of 75-100 kDa (Table 4, Fig. 2). Q-PCR showed expression of $S V 2 A$ in all GISTs, with median values similar to those observed in well differentiated endocrine carcinomas (WDEC) of the ileum/carcinoids, and two orders of magnitude higher than those observed in colorectal adenocarcinomas (Table 5 and Fig. 3). The localization of SV2 in GIST and normal ICC was further studied by confocal laser scanning microscopy (Fig. 4). In GIST, a granular SV2 staining was observed in the cytoplasm of KIT positive tumor cells. In normal intestine, no SV2 staining could be detected in KIT positive ICC. However, a close spatial relationship between SV2 positive nerve terminals and KIT positive ICC was demonstrated.

Synapsin 1 was observed in the majority of GISTs (Table 3). In tumors, strong staining was seen predominantly in tumor cell neurite- and bouton-like structures (Fig. 1). Q-PCR showed expression of
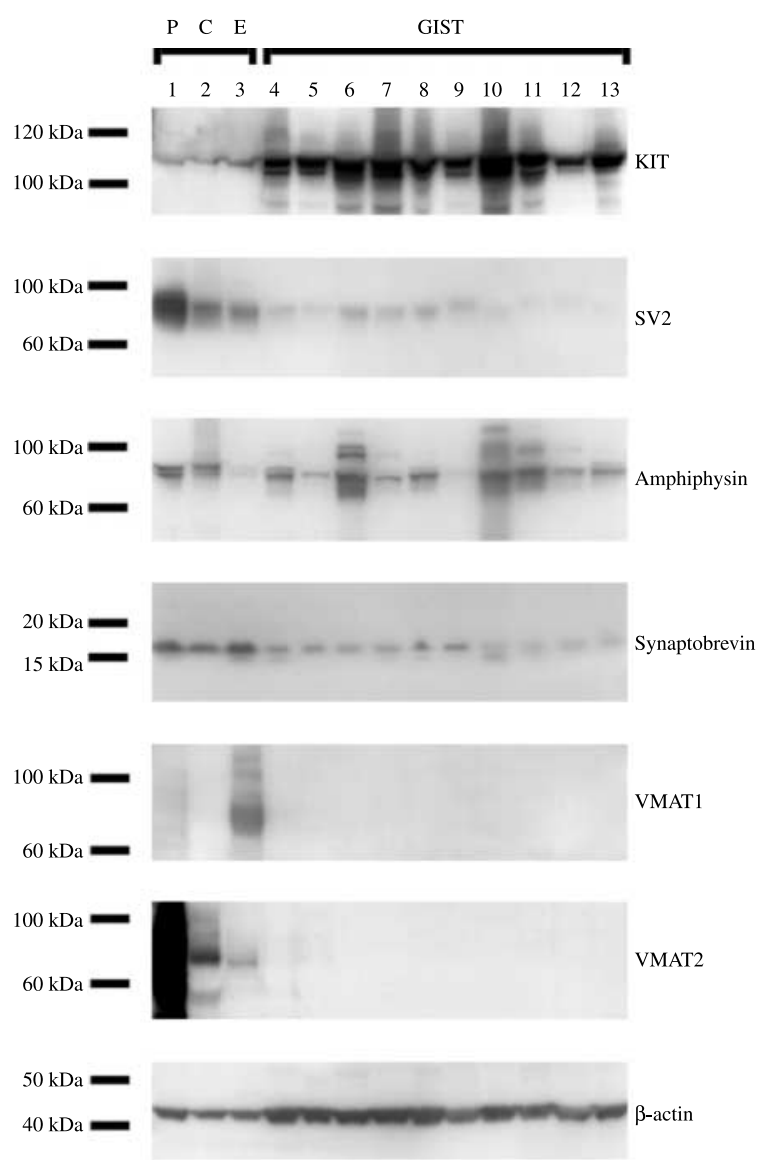

Figure 2 Expression of KIT and synaptic vesicle proteins in GISTs. Western blotting demonstrated KIT immunoreactive bands with apparent molecular weights of 104 and $108 \mathrm{kDa}$. SV2, amphiphysin, and synaptobrevin showed immunoreactive bands in the range of $75-100,85-155$, and $15 \mathrm{kDa}$ respectively. VMAT1 and VMAT2 were demonstrated in control tumors but were undetectable in GISTs. Both low-risk profile GISTs (lane 4, 5, 7 and 8) and high-risk profile GISTs (lane 6, 9-13) were analyzed. Adrenal pheochromocytoma (P), WDEC/midgut carcinoid (C), and endocrine pancreatic carcinoma $(E)$ served as control tumors. $\beta$-Actin was used as internal control. 


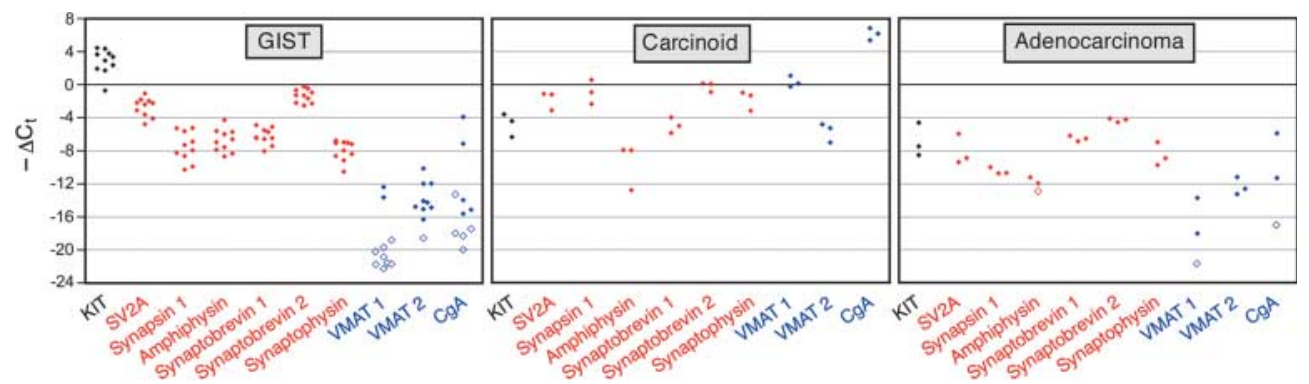

Figure 3 Scatter plots of KIT and synaptic vesicle protein expression in GISTs. Expression of SLMV markers (red) was higher than the expression of LDCV markers (blue). WDEC/midgut carcinoid ('carcinoid') and colorectal adenocarcinoma ('adenocarcinoma') served as control tumors. Log-transformed gene expression ratios obtained from Q-PCR analysis are plotted. Each dot represents data derived from one sample. Unfilled dots represent expression values below the detection limit.

synapsin 1 in all GISTs, with median values two orders of magnitude lower than those observed in WDEC of the ileum/carcinoids, but one order of magnitude higher than those observed in colorectal adenocarcinomas (Table 5 and Fig. 3).

Positive staining for amphiphysin was observed in the majority of GISTs (Table 3). Moderate staining was seen in the majority of tumor cells, with a granular cytoplasmic pattern and frequently with perinuclear localization (Fig. 1). In GISTs, amphiphysin migrated as multiple bands, with a major band of $\sim 85 \mathrm{kDa}$, and minor bands of 110,120 and $155 \mathrm{kDa}$ (Table 4 and Fig. 2). Q-PCR showed expression of amphiphysin in all GISTs with median values similar to those observed in WDEC of the ileum/carcinoids and one order of magnitude higher than those observed in colorectal adenocarcinomas (Table 5 and Fig. 3).

Positive staining for synaptobrevin was observed in the majority of GISTs (Table 3). A moderate number of tumor cells were stained. Moderate staining with a granular pattern was seen in the tumor cell cytoplasm (Fig. 1). In GISTs, synaptobrevin migrated as a major band of $\sim 15 \mathrm{kDa}$ (Table 4 and Fig. 2). Q-PCR showed expression of synaptobrevin 1 and 2 in all GISTs. The expression values for synaptobrevin 2 were one order of magnitude higher than those for synaptobrevin 1. Expression values for synaptobrevin 1 and 2 in GISTs were similar to those in WDEC of the ileum/carcinoids (Table 5 and Fig. 3).

Synaptophysin, synapsin 2A, syntaxin, SNAP-25, and GAP-43 could not be demonstrated by IHC, but expression of synaptophysin was detected by Q-PCR in all GISTs, although with median values two orders of magnitude lower than those observed in WDEC of the ileum/carcinoids and similar to those observed in colorectal adenocarcinomas.

\section{LDCV proteins are not regularly expressed in GIST}

LDCV proteins were demonstrated in a minority of GISTs (Table 3). CgA was undetectable in all GISTs by IHC (Table 3). Q-PCR showed expression of $C g A$ in five GISTs, with median values five orders of magnitude lower than those in WDEC of the ileum/ carcinoids and similar to those observed in colorectal adenocarcinomas. VMAT1 was negative in the majority of GISTs, but a small number of tumor cells were stained in one-third of the tumors (Table 3). Moderate staining was observed in the cytoplasm of tumor cells, predominantly localized to the perinuclear area (Fig. 1). VMAT2 was undetectable in all GISTs by IHC. Western blot analysis was negative for both VMAT1 and VMAT2 (Table 4). Q-PCR detected expression of VMATl in only two GISTs. The expression levels of VMAT 1, in these two tumors were four orders of magnitude lower than those observed in WDEC of the ileum/carcinoids, and similar to those observed in colorectal

Table 4 Expression of synaptic vesicle protein 2 (SV2), amphiphysin, vesicular monoamine transporter (VMAT) 1 \& 2, and synaptobrevin in gastrointestinal stromal tumors (GISTs) studied by western blot

\begin{tabular}{llcc}
\hline Marker & \multicolumn{1}{c}{ Protein } & $\begin{array}{c}\text { L, Im GIST } \\
(n=4)\end{array}$ & $\begin{array}{c}\text { H, OM GIST } \\
(n=6)\end{array}$ \\
\hline \multirow{2}{*}{ SLMV } & SV2 & $4 / 4$ & $6 / 6$ \\
& Synapsin 1 & $0 / 4$ & $0 / 6$ \\
& Amphiphysin & $4 / 4$ & $5 / 6$ \\
& Synaptobrevin & $4 / 4$ & $6 / 6$ \\
LDCV & VMAT1 & $0 / 4$ & $0 / 6$ \\
& VMAT2 & $0 / 4$ & $0 / 6$ \\
\hline
\end{tabular}

Values represent the number of positive tumors/total number of tumors analyzed. 
Table 5 Number of target copies per 1000 copies of $\beta$-actin

\begin{tabular}{llccc}
\hline Marker & \multicolumn{1}{c}{ Gene } & $\begin{array}{c}\text { GIST } \\
(n=10)\end{array}$ & $\begin{array}{c}\text { WDECI } \\
\text { carcinoid } \\
(n=3)\end{array}$ & $\begin{array}{c}\text { CR adeno- } \\
\text { carcinoma } \\
(n=3)\end{array}$ \\
\hline GIST & KIT & 9100 & 48 & 5.7 \\
SLMV & SV2A & 210 & 440 & 2.2 \\
& Synapsin I & 5.3 & 540 & 0.6 \\
& Amphiphysin & 9.3 & 4.2 & $-{ }^{\mathrm{a}}$ \\
& Synaptobrevin 1 & 12 & 32 & 11 \\
& Synaptobrevin 2 & 420 & 1100 & 53 \\
& Synaptophysin & 5.5 & 410 & 2.1 \\
LDCV & VMAT1 & $-{ }^{\mathrm{b}}$ & 1100 & $-{ }^{\mathrm{a}}$ \\
& VMAT2 & 0.05 & 26 & 0.2 \\
& CgA & 0.1 & 74000 & $-{ }^{\mathrm{a}}$ \\
\hline
\end{tabular}

$\mathrm{CgA}$, chromogranin A; CR, colorectal; SV2A, synaptic vesicle protein 2A; VMAT 1 and 2, vesicular monoamine transporter 1 and 2; WDEC, well differentiated endocrine carcinoma.

${ }^{a} A$ bove detection limit in only two out of ten tumors.

${ }^{\mathrm{b}}$ Above detection limit in two out of three tumors. The values shown are median. adenocarcinomas. Expression of VMAT 2 was detected in all but one GIST, with median values three orders of magnitude lower than those observed in WDEC of the ileum/carcinoids, and one order of magnitude lower than those observed in colorectal adenocarcinomas (Table 5 and Fig. 3).

\section{Ultrastructural evidence for SLMV in GIST}

Analysis of GIST by electron microscopy demonstrated presence of numerous vesicles in tumor cells. The majority of the vesicles was of clear type with an approximate diameter of $40-80 \mathrm{~nm}$ and located predominantly in perinuclear and Golgi areas. The ultrastructural appearance was consistent with that of SLMV. In some tumor cells, vesicles with an approximate diameter of $80-120 \mathrm{~nm}$ and an electron dense core were also demonstrated (Fig. 5).
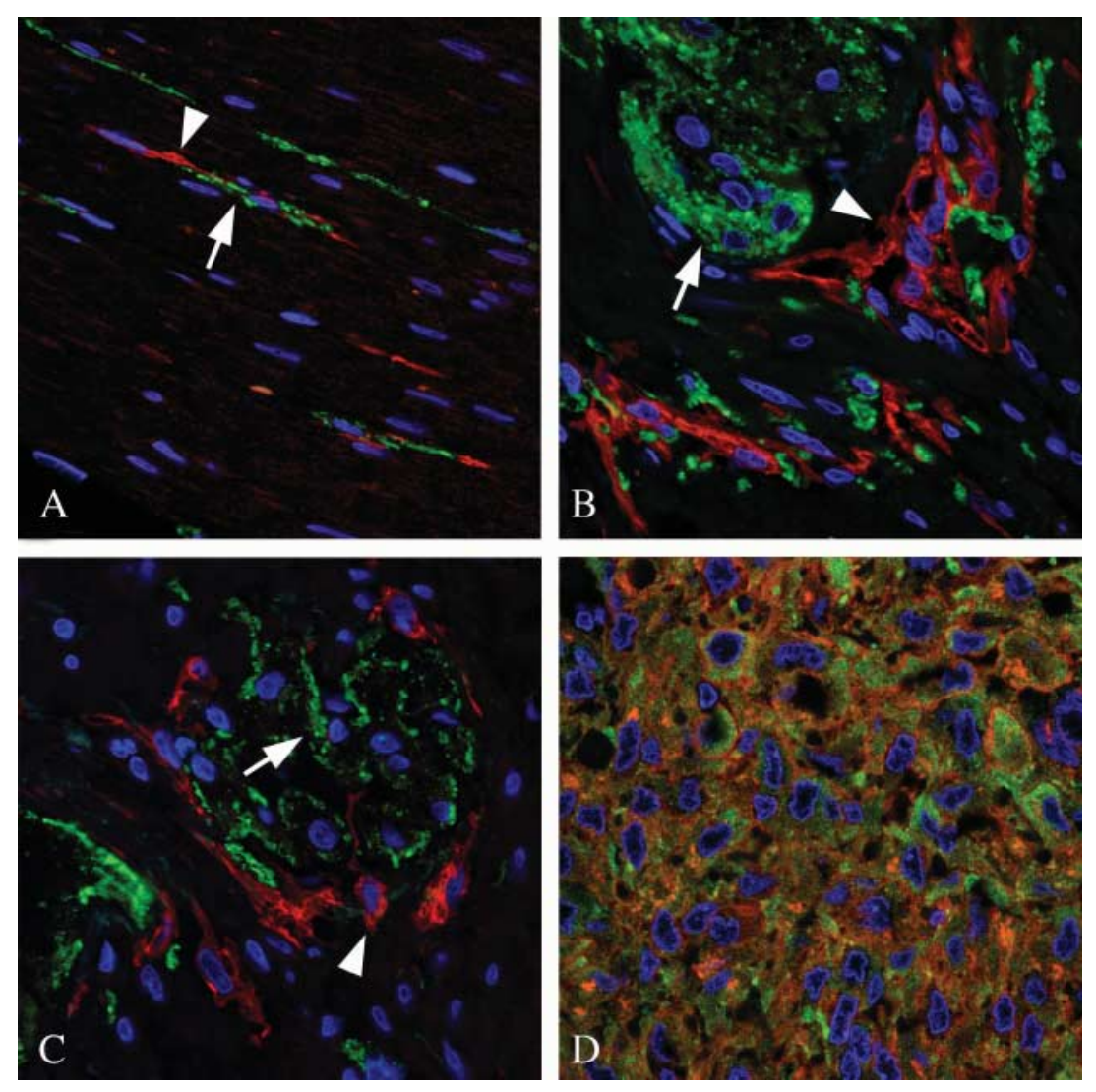

Figure 4 Co-localization of SV2 and KIT in GIST and normal intestine. SV2 (green), KIT (red), and cell nuclei (blue) were examined by confocal laser scanning microscopy. (A) Normal small intestine, muscularis propria. SV2 positive nerve terminals (arrow) surround KIT positive ICC (arrowhead). (B and C) Normal small intestine, myenteric plexus. Numerous SV2 positive nerve terminals are found in the myenteric plexus (arrow). ICC (arrowhead) are positive for KIT but negative for SV2. (D) High-risk GIST. SV2 and KIT are colocalized to the same tumor cells. SV2 demonstrated a granular cytoplasmic labeling of tumor cells, while KIT displayed membrane labeling of tumor cells. 

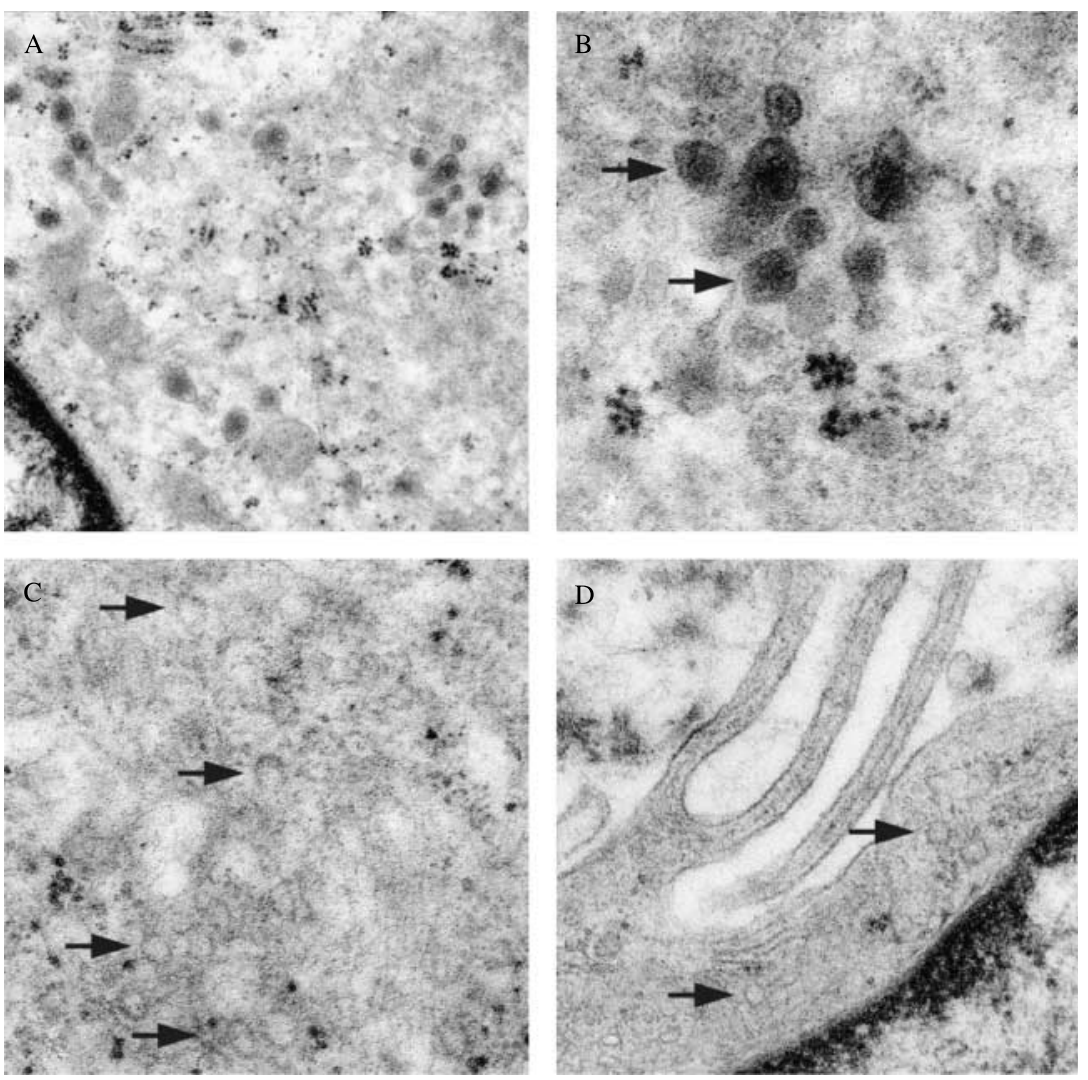

Figure 5 Ultrastructural demonstration of cytoplasmic vesicles in high-risk GIST. (A) Electron microscopy demonstrated numerous vesicles in the perinuclear area of tumor cells. (B) Some vesicles measured $80-120 \mathrm{~nm}$ and contained a dense core (arrows). (C and D) The majority of vesicles measured $40-80 \mathrm{~nm}$ and were of clear type (arrows). Original magnification $30000 \times$ (A) and $80000 \times(B-D)$.

\section{Lack of correlation between expression of SLMV and clinicopathological features in GIST}

There were no significant differences in the staining pattern, molecular size or expression levels of SLMV proteins when low- and high-risk profile GISTs were compared. Similarly, there were no significant differences in SLMV protein expression between GISTs with wild-type KIT/PDGFRA and mutated KIT/PDGFRA.

\section{Discussion}

Regulated secretion of transmitters and hormones is regarded as the hallmark of neuroendocrine cells and tumors. In addition, specific hormone production is frequently demonstrated in these tumors. In this study, we demonstrate expression of SV2, synaptobrevin, synapsin 1, and amphiphysin in a majority of GISTs regardless of tumor site, risk profile or KIT/PDGFRA mutational status. Expression of these SLMV proteins, in addition to ghrelin, and its receptor (Ekeblad et al.
2006), suggests and give evidence for a neuroendocrine phenotype.

The diagnosis and classification of neuroendocrine tumors requires a combination of morphological analysis and demonstration of one or several of the synaptic vesicle protein known to be involved in the regulated secretory pathway. Traditionally, the presence of $\mathrm{CgA}$ and/or synaptophysin has been a prerequisite for the histopathological diagnosis of neuroendocrine tumors.

In recent years, multiple synaptic vesicle protein besides $\mathrm{CgA}$ and synaptophysin have been demonstrated in neuroendocrine tumors, e.g., SV2 (Portela-Gomes et al. 2000, Jakobsen et al. 2002), VMAT 1 and 2 (Jakobsen et al. 2001), and amphiphysin (Zanner et al. 2004). The expression of several SLMV proteins in GIST therefore suggests that these tumors have a neural or neuroendocrine differentiation. This is further supported by the observation of numerous clear vesicles in GIST having an ultrastructural appearance of SLMV. 
Quantitation of synaptic vesicle protein by Q-PCR revealed specific expression patterns in GIST, WDEC/ carcinoids and colorectal adenocarcinomas. In WDEC/carcinoids, both LDCV and SLMV proteins were highly expressed, while in GIST only SLMV proteins were shown to be highly expressed. Colorectal adenocarcinomas showed low expression of both LDCV and SLMV proteins. Q-PCR analysis readily distinguished the three tumor types in this study and the technique may prove to be a useful tool to complement IHC in the molecular characterization of tumors (Kidd et al. 2006).

Neuroendocrine differentiation, i.e., positive $\mathrm{CgA}$ and/or synaptophysin staining has been documented in some non-endocrine tumors, e.g., prostatic carcinoma (Hirano et al. 2005), breast carcinoma (van Krimpen et al. 2004), and gastrointestinal carcinoma (Grabowski et al. 2002). However, in non-endocrine tumors, neuroendocrine differentiation is usually demonstrated in a small subset of tumor cells. Neuroendocrine differentiation in some types of non-endocrine tumors has been associated with poor prognosis (Di Sant'Agnese 2001). In this series, we could not detect any correlation between tumor site, risk profile, or KIT/PDGFRA mutational status and expression of synaptic vesicle protein. The significance of SLMV expression in GIST is currently unknown and must be explored further. Confocal laser scanning microscopy failed to demonstrate the synaptic vesicle protein SV2 in ICC, while this technique readily demonstrated SV2 in GIST. This finding suggests that SLMV protein expression in ICC is low or absent, and that expression of SLMV proteins is up-regulated during transformation and development of GIST.

The regulated secretion in neuroendocrine cells and tumors is controlled by $\mathrm{G}$ protein-coupled membrane receptors. High expression of $\mathrm{G}$ protein-coupled receptors, e.g., somatostatin receptors, has been demonstrated in neuroendocrine tumors (Barnett 2003) and GIST (Montella et al. 2005). Extremely high densities of bombesin subtype 2 (gastrinreleasing peptide-GRP)-receptors, vasoactive intestinal peptide subtype 2-receptors, and cholecystokinin subtype 2-receptors have been demonstrated in the majority of GISTs (Reubi et al. 2004), further supporting the presence of a regulated secretion in GIST. In the future, radiolabeled peptides/analogs may be used for both localization and targeted treatment of GIST, especially in patients who are not responsive to treatment with tyrosine kinase inhibitors.
In conclusion, our study shows that GISTs regularly express SLMV proteins, indicating a neuroendocrine phenotype. This suggests that novel strategies of treatment of these tumors may soon be a reality.

\section{Acknowledgements}

We wish to thank Johanna Andersson, Ellinor Andersson, Malin Berntsson and Ann-Christin IllerskogLindström for their expert technical assistance.

Supported by the Swedish Cancer Society, Swedish Research Council (5220), Sahlgrenska Academy (the government ALF agreement), the Inga-Britt and Arne Lundberg Research Foundation, the Johan Jansson Foundation for Cancer Research, the Assar Gabrielsson Research Foundation, Göteborg Medical Society, the King Gustav V Jubilee Clinical Cancer Research Foundation, and Sahlgrenska University Hospital Research Foundation. The authors do not have any financial or personal relationships between themselves that might bias this work.

\section{References}

Andersson J 2005 Gastrointestinal stromal tumours pathogenetic mechanisms, phenotypic characterization and prognosis. PhD thesis, Sahlgrenska Academy at Göteborg University, Sweden.

Barnett P 2003 Somatostatin and somatostatin receptor physiology. Endocrine 3 255-264.

Ekeblad S, Nilsson B, Lejonklou MH, Johansson T, Stålberg P, Nilsson O, Ahlman H \& Skogseid B 2006 Gastrointestinal stromal tumours express the orexigen ghrelin. EndocrineRelated Cancer 13 963-970.

Erlandson RA, Klimstra DS \& Woodruff JM 1996 Subclassification of gastrointestinal stromal tumours based on evaluation by electron microscopy and immunohistochemistry. Ultrastructural Pathology 20 373-393.

Fletcher CD, Berman JJ, Corless C, Gorstein F, Lasota J, Longley BJ, Miettinen M, O’Leary TJ, Remotti H, Rubin BP et al. 2002 Diagnosis of gastrointestinal stromal tumours: a consensus approach. Human Pathology $\mathbf{3 3}$ 459-465.

Grabowski P, Schonfelder J, Ahnert-Hilger G, Foss HD, Heine B, Schindler I, Stein H, Berger G, Zeitz M \& Scherubl H 2002 Expression of neuroendocrine markers: a signature of human undifferentiated carcinoma of the colon and rectum. Virchows Archiv 441 256-263.

Hirano D, Jike T, Okada Y, Minei S, Sugimoto S, Yamaguchi K, Yoshikawa T, Hachiya T, Yoshida T \& Takimoto Y 2005 Immunohistochemical and 
ultrastructural features of neuroendocrine differentiated carcinomas of the prostate: an immunoelectron microscopic study. Ultrastructural Pathology 29 367-375.

Hirota S, Isozaki K, Moriyama Y, Hashimoto K, Nishida T, Ishiguro S, Kawano K, Hanada M, Kurata A, Takeda M et al. 1998 Gain-of-function mutations of c-kit in human gastrointestinal stromal tumors. Science 279 577-580.

Huizinga JD, Thuneberg L, Kluppel M, Malysz J, Mikkelsen $\mathrm{HB} \&$ Bernstein A 1995 W/kit gene required for interstitial cells of Cajal and for intestinal pacemaker activity. Nature 373 347-349.

Jahn R, Schiebler W, Ouimet C \& Greengard P 1985 A 38,000-dalton membrane protein (p38) present in synaptic vesicles. PNAS 82 4137-4141.

Jakobsen AM, Andersson P, Saglik G, Andersson E, Kölby L, Erickson JD, Forssell-Aronsson E, Wängberg B, Ahlman H \& Nilsson O 2001 Differential expression of vesicular monoamine transporter (VMAT) 1 and 2 in gastrointestinal endocrine tumours. Journal of Pathology 4 463-472.

Jakobsen AM, Ahlman H, Wängberg B, Kölby L, Bengtsson M \& Nilsson O 2002 Expression of synaptic vesicle protein 2 (SV2) in neuroendocrine tumours of the gastrointestinal tract and pancreas. Journal of Pathology 196 44-50.

Kidd M, Modlin IM, Mane SM, Camp RL \& Shapiro MD 2006 Q RT-PCR detection of chromogranin A: a new standard in the identification of neuroendocrine tumor disease. Annals of Surgery 243 273-280.

Kindblom LG, Remotti HE, Aldenborg F \& Meis-Kindblom JM 1998 Gastrointestinal pacemaker cell tumor (GIPACT): gastrointestinal stromal tumors show phenotypic characteristics of the interstitial cells of Cajal. American Journal of Pathology 152 1259-1269.

Kölby L, Bernhardt P, Ahlman H, Wängberg B, Johanson V, Wigander A, Forssell-Aronsson E, Karlsson S, Ahren B, Stenman G et al. 2001 A transplantable human carcinoid as model for somatostatin receptor-mediated and amine transporter-mediated radionuclide uptake. American Journal of Pathology 158 745-755.

Komuro T 1999 Comparative morphology of interstitial cells of Cajal: ultrastructual characterization. Microscopy Research and Technique 47 267-285.

van Krimpen C, Elferink A, Broodman CA, Hop WC, Pronk A \& Menke M 2004 The prognostic influence of neuroendocrine differentiation in breast cancer: results of a long-term follow-up study. Breast 13 329-333.
Lee JR, Joshi V, Griffin JW Jr, Lasota J \& Miettinen M 2001

Gastrointestinal autonomic nerve tumor: immunohistochemical and molecular identity with gastrointestinal stromal tumor. American Journal of Surgical Pathology 25 979-987.

Lloyd RV \& Wilson BS 1983 Specific endocrine tissue marker defined by a monoclonal antibody. Science $\mathbf{2 2 2}$ 628-630.

Montella L, Florio T, Aiello C, Barbieri F, Villa V, Schulz S et al. 2005 Somatostatin receptor expression in stromal tumors of the gastrointestinal tract. Proceedings of the American Society of Clinical Oncology (Abstract no. 9042).

Nilsson B, Bumming P, Meis-Kindblom JM, Oden A, Dortok A, Gustavsson B, Sablinska K \& Kindblom LG 2005 Gastrointestinal stromal tumors: the incidence, prevalence, clinical course, and prognostication in the preimatinib mesylate era. Cancer 103 821-829.

Portela-Gomes GM, Lukinius A \& Grimelius L 2000 Synaptic vesicle protein 2. A new neuroendocrine cell marker. American Journal of Pathology 157 1299-1309.

Reubi JC, Korner M, Waser B, Mazzucchelli L \& Guillou L 2004 High expression of peptide receptors as a novel target in gastrointestinal stromal tumours. European Journal of Nuclear Medicine and Molecular Imaging 31 803-810.

Rindi G, Leiter AB, Kopin AS, Bordi C \& Solcia E 2004 The 'normal' endocrine cell of the gut: changing concepts and new evidences. Annals of the New York Academy of Sciences 1014 1-12.

Di Sant'Agnese PA 2001 Neuroendocrine differentiation in prostatic carcinoma: an update on recent developments. Annals of Oncology 12 135-140.

Sircar K, Hewlett BR, Huizinga JD, Chorneyko K, Berezin I \& Riddell RH 1999 Interstitial cells of Cajal as precursors of gastrointestinal stromal tumors. American Journal of Surgical Pathology 23 377-389.

Vannucchi MG 1999 Receptors in interstitial cells of Cajal: identification and possible physiological roles. Microscopy Research and Technique 47 325-335.

Zanner R, Gratzl M \& Prinz C 2004 Expression of the endocytic proteins dynamin and amphiphysin in rat gastric enterochromaffin-like cells. Journal of Cell Science 11 2369-2376. 